\title{
Comparison of Left Radial Versus Femoral Approaches for Coronary Procedures in Patients with Previous Coronary Artery Bypass Grafts
}

\author{
SR Khan, *CMSKabir, MZ Chowdhury ${ }^{3}, \mathrm{MJ} \mathrm{Iqbal}^{4}, \mathrm{MM} \mathrm{Haq}^{5}, \mathrm{ML} \mathrm{Ali}^{6}, \mathrm{MR} \mathrm{Karim}^{7}$
}

\begin{abstract}
Aims: Radial approach is gaining the momentum as a default technique for coronary procedures. Limited trails are available for post coronary artery bypass graft $(\mathrm{CABG})$ patients to compare the merits of femoral $\&$ radial access.

Methods: It is a single-center study conducted in between January, 2013 to December, 2015. During this study period, post CABG patients were blindly assigned to its five high volume operators. Coronary angiography \& intervention procedures were performed by left radial or femoral approach as per assigned operator's choice. Contrast volume was the primary endpoint whereas the procedure \& fluoroscopy time, procedural success, access site major bleeding, pre discharge major adverse cardiac event (MACE) were the secondary endpoint both for coronary angiogram (CAG) \& percutaneous coronary intervention (PCI).

Results: Total 380 post CABG patients were included in this study period. Radial access $(n=155)$ was lower than femoral access $(n=225)$. Compared with femoral access, diagnostic CAG required relatively lower contrast volume though statistically not significant via radial access $(70 \pm 34$ vs. $72 \pm 40 \mathrm{ml}, \mathrm{p}=0.267)$. Procedure time $(25.2 \pm 10.7$ vs. $26.9 \pm 6.8 \mathrm{~min}, \mathrm{p}=0.735)$, fluoroscopy time $(10.7 \pm 5.5$ vs. $9.5 \pm 4.7 \mathrm{~min}$, $\mathrm{p}=0.424)$ were almost similar in both access for CAG. Other secondary clinical endpoints were similar among both groups. Interestingly, adhoc PCI was more frequent in radial group $(\mathrm{n}=54$ out of 155, 34.8\%) than in femoral group $(n=44$ out of $225,19.6 \%)$ with $\mathrm{p}=0.01$. Contrast volume in between two groups was pretty similar with $p=0.226$. The incidence of other secondary endpoints was also not statistically significant.

Conclusion: Coronary angiography for post CABG patients through left radial approach seems to be effective, non-inferior in terms of contrast volume, procedure \& fluoroscopy time \& other clinical end points comparing to femoral access.
\end{abstract}

Key Words: Coronary artery bypass graft, transfemoral, transradial.

${ }^{1}$ Dr Saidur Rahman Khan, Associate Professor \& Senior Consultant in Cardiology, Ibrahim Cardiac Hospital \& Research Institute, Shahbag, Dhaka-1000

$2 * \operatorname{Dr} C$ M Shaheen Kabir, Assistant Professor \& Associate Consultant in Cardiology, Ibrahim Cardiac Hospital \& Research Institute, Shahbag, Dhaka-1000.e-mail: skabir67@yahoo.com

${ }^{3}$ Dr Mashhud Zia Chowdhury, Associate Professor \& Senior Consultant, Ibrahim Cardiac Hospital \& Research Institute, Shahbag, Dhaka-1000

${ }^{4} \mathrm{Dr}$ Md Jabed Iqbal, Associate Consultant, Ibrahim Cardiac Hospital \& Research Institute, Shahbag, Dhaka-1000

${ }^{5}$ Dr M Maksumul Haq, Professor \& Head, Department of Cardiology, Ibrahim Cardiac Hospital \& Research Institute, Shahbag, Dhaka-1000

${ }^{6} \mathrm{Dr}$ Mohammad Liaquat Ali, Professor \& Senior Consultant, Ibrahim Cardiac Hospital \& Research Institute, Shahbag, Dhaka-1000

${ }^{7}$ Dr Md Rezaul Karim, Professor \& Senior Consultant, Ibrahim Cardiac Hospital \& Research Institute, Shahbag, Dhaka-1000

*Corresponding Author

Date of submission: 06.02.2018 Date of acceptance: 17.05.2018

AKMMC J 2019; 10(1) : 11-16 


\section{Introduction}

Among patients undergoing coronary procedures, patients with coronary artery bypass grafts (CABG) represent an important, high risk subgroup. Routine transradial approach (TRA) may be successfully adopted in these patients to reduce access site complications. Coronary angiography (CAG) via TRA has gained growing acceptance and operator preference in recent years, based on a reduction in vascular complications and mortality 1,2 when compared with transfemoral approach (TFA). However, it has been suggested that these advantages come at the cost of increased procedure time and fluoroscopy dose. ${ }^{3-5}$ Considering the significant morbidity and mortality benefits, increased patient preference and cost effectiveness, 6,7 the European Society of Cardiology now advocates the TRA as the default access route for coronary angiography. ${ }^{8}$ Some parts of the world, including the United States, have been slower to adopt this practice. In 2009, less than 5\% of coronary procedures were performed via TRA $;{ }^{9}$ however, this figure has increased substantially in recent years, with estimates that around $20 \%$ of procedures are now performed radially. ${ }^{10}$ Studies comparing access route preference mainly involve native coronary vessel angiograms, mostly excluding patients post CABG surgery. Although there is insufficient evidence to advocate TRA for patients with coronary grafts, both native arteries and grafts, including the left internal mammary artery, can be commonly studied from the left radial artery. We sought to compare left TRA with standard TFA for post-CABG patients with respect to procedure and fluoroscopy time.

\section{Materials \& Methods}

A retrospective analysis was undertaken of demographic and procedural variables of all patients with past CABG surgery who underwent diagnostic CAG \&percutaneous coronary intervention (PCI) at our institution, Ibrahim Cardiac Hospital \& Research Institute (ICHRI) between January 2013 \&December 2015. The study protocol was approved by the Ethics Committee of ICHRI.Cardiology trainees were equally involved in both TRA and
TFA cases during the study and were supervised throughout, with prompt consultant intervention if two failed access attempts or difficulties during the procedure occurred. Choice of TRA or TFA was at the consultant operator's discretion.

For TRA catheterization, a satisfactory Allen's test result was confirmed. After subcutaneous local anesthesia, the radial artery was cannulated with a 6 FrRadifocus introducer sheath (Terumo Corporation). Then, $5000 \mathrm{U}$ of intraarterial unfractionated heparin and $2.5 \mathrm{mg}$ of intraarterial verapamil were administered. Radial hemostasis was subsequently obtained using digital pressure. Femoral arteries were cannulated similarly with 7Fr sheaths and hemostasis was later obtained by digital pressure. Contrast volume was the primary endpoint whereas the procedure \& fluoroscopy time, procedural success, access site major bleeding, pre discharge MACE were the secondary endpoint both for CAG \& PCI.

Continuous variables are presented as means and categorical variables as counts and percentages. Statistical analysis was done using a combination of t-test, Chi-square test and Fisher's exact test. Differences between groups were statistically significant at a $p$-value $<0.05$. SPSS 17.0 statistical software was employed for the analysis.

\section{Results}

Total 380 post CABG patients were included in this study period. Radial access $(n=155)$ was lower than femoral access $(n=225)$. There were no significant difference with regard to age, gender, prior MI, prior PCI and diabetes between TRA and TFA. The mean value of LVEF was also similar (table I). Compared with femoral access, diagnostic CAG required relatively lower contrast volume though statistically not significant via radial access $(70 \pm 34$ vs. $72 \pm 40 \mathrm{ml}$, $\mathrm{p}=0.267)$. Procedure time $(25.2 \pm 10.7$ vs. $26.9 \pm 6.8$ min, $\mathrm{p}=0.735)$, fluoroscopy time $(10.7 \pm 5.5$ vs. $9.5 \pm 4.7$ min, $\mathrm{p}=0.424$ ) were almost similar in both access for CAG (Table II). Other secondary clinical endpoints were similar among both grou 
Table 1: Demographic \& baseline characteristics of the study population

\begin{tabular}{lccc}
\hline Characteristics & $\begin{array}{c}\text { Radial access } \\
(\mathbf{n}=\mathbf{1 5 5})\end{array}$ & $\begin{array}{c}\text { Femoral access } \\
(\mathbf{n = 2 2 5})\end{array}$ & P value \\
\hline Age, yrs & $60.7 \pm 8.9$ & $60.3 \pm 8.2$ & 0.555 \\
Men, \% & $129(83.2 \%)$ & $181(80.4 \%)$ & 0.089 \\
BMI, Kg/m ${ }^{2}$ & $26.1 \pm 4.4$ & $25.7 \pm 3.4$ & 0.479 \\
Clinical presentation & & & \\
SA & $75(48.4 \%)$ & $88(39.1 \%)$ & 0.103 \\
UA & $23(14.8 \%)$ & $39(17.3 \%)$ & 0.736 \\
NSTEMI & $36(23.2 \%)$ & $60(26.7 \%)$ & 0.633 \\
Others & $23(14.8 \%)$ & $39(17.3 \%)$ & 0.736 \\
HTN & $122(78.7 \%)$ & $164(72.9 \%)$ & 0.368 \\
DL & $59(38.1 \%)$ & $86(38.2 \%)$ & 0.735 \\
DM & $109(70.3 \%)$ & $167(72.9 \%)$ & 0.583 \\
HF & $24(15.5 \%)$ & $2511.1 \%)$ & 0.424 \\
No of years since CABG & $5.2 \pm 0.8$ & $5.9 \pm 1.2$ & 0.221 \\
Previous MI & $29(18.7 \%)$ & $43(19.2 \%)$ & 0.883 \\
Previous PCI & $14(9.0 \%)$ & $11(4.9 \%)$ & 0.267 \\
Previous stroke & $4(2.6 \%)$ & $1(0.4 \%)$ & 0.197 \\
CKD & $18(11.6 \%)$ & $18(8.0 \%)$ & 0.471 \\
PAD & $1(0.6 \%)$ & $5(2.2 \%)$ & 0.475 \\
EF\% & $50.7 \pm 9.2$ & $51.4 \pm 9.8$ & 0.469 \\
\hline
\end{tabular}

Table 2: Procedural characteristics

\begin{tabular}{lccc} 
Characteristics & $\begin{array}{c}\text { Radial access } \\
(\mathbf{n}=\mathbf{1 5 5})\end{array}$ & $\begin{array}{c}\text { Femoral access } \\
(\mathbf{n = 2 2 5})\end{array}$ & P value \\
\hline Contrast volume, ml & $70 \pm 34$ & $72 \pm 40$ & 0.267 \\
Procedure time, min & $25.2 \pm 10.7$ & $26.9 \pm 6.8$ & 0.735 \\
Fluoroscopy time, min & $10.7 \pm 5.5$ & $9.5 \pm 4.7$ & 0.424 \\
\hline
\end{tabular}

Table 3: Procedural outcomes in patients undergoing diagnostic CAG

\begin{tabular}{lccc}
\hline Characteristics & $\begin{array}{c}\text { Radial access } \\
(\mathbf{n = 1 5 5})\end{array}$ & $\begin{array}{c}\text { Femoral access } \\
(\mathbf{n = 2 2 5})\end{array}$ & P value \\
\hline No of patent grafts & $1.7 \pm 1.0$ & $1.7 \pm 0.9$ & 0.567 \\
No patent graft & $9(5.8 \%)$ & $16(7.1 \%)$ & \\
1 patent graft & $58(37.4 \%)$ & $78(34.7 \%)$ & \\
2 patent graft & $59(38.1 \%)$ & $84(37.3 \%)$ & \\
3 patent graft & $28(18.1 \%)$ & $41(18.2 \%)$ & \\
4 patent graft & $1(0.6 \%)$ & $5(2.2 \%)$ & \\
5 patent graft & - & $1(0.4 \%)$ & \\
No of diagnostic & $1.9 \pm 0.7$ & $2.5 \pm 1.3$ & 0.529 \\
catheters used & & & \\
\hline
\end{tabular}

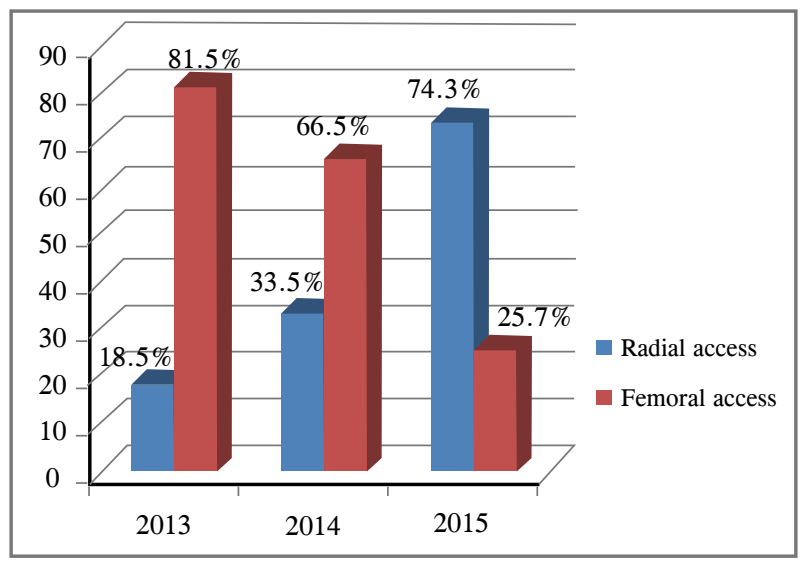

Figure 1: Access preference of study population, 2013-201

Table 4: Procedural outcomes in patients undergoing PCI

\begin{tabular}{|c|c|c|c|}
\hline Characteristics & $\begin{array}{l}\text { Radial access } \\
\qquad(\mathrm{n}=54)\end{array}$ & $\begin{array}{l}\text { Femoral access } \\
\qquad(n=44)\end{array}$ & $P$ value \\
\hline No of lesions treated & $1.2 \pm 0.53$ & $1.1 \pm 0.56$ & \multirow{4}{*}{0.583} \\
\hline 1 lesion treated & $43(79.7 \%)$ & $36(81.4 \%)$ & \\
\hline 2 lesion treated & $11(20.4 \%)$ & $7(15.9 \%)$ & \\
\hline 3 lesion treated & - & $1(2.3 \%)$ & \\
\hline No of stents used & $1.3 \pm 0.8$ & $1.3 \pm 0.7$ & \multirow{5}{*}{0.194} \\
\hline 1 stent used & $36(66.7 \%)$ & $27(31.4 \%)$ & \\
\hline 2 stent used & $14(25.9 \%)$ & $10(22.7 \%)$ & \\
\hline 3 stent used & $3(5.6 \%)$ & $3(6.8 \%)$ & \\
\hline 4 stent used & - & $1(2.3 \%)$ & \\
\hline Aveg stent length, mm & $29.8 \pm 15.4$ & $31.2 \pm 16.5$ & 0.689 \\
\hline No of balloons used & $1.2 \pm 0.9$ & $1.3 \pm 1.5$ & 0.404 \\
\hline Stent deployment & $53(96.3 \%)$ & $41(93.2 \%)$ & 0.002 \\
\hline POBA & $4(7.4 \%)$ & $6(13.6 \%)$ & 0.985 \\
\hline \multirow{2}{*}{\multicolumn{4}{|c|}{$\begin{array}{l}\text { Target vessel } \\
\text { intervention }\end{array}$}} \\
\hline & & & \\
\hline SVG & $13(24.1 \%)$ & $13(29.5 \%)$ & 0.590 \\
\hline $\mathrm{LCx}$ & $22(38.9 \%)$ & $16(36.4 \%)$ & 0.073 \\
\hline $\mathrm{RCA}$ & $19(35.2 \%)$ & $18(40.9 \%)$ & 0.367 \\
\hline LAD & $10(18.5 \%)$ & $3(6.8 \%)$ & 0.026 \\
\hline LIMA & $3(5.6 \%)$ & $3(6.8 \%)$ & 0.891 \\
\hline
\end{tabular}

No significant difference was found in terms of mean number, type or severity of the atherosclerosis of the grafts between the TRA and TFA (table III). Interestingly, adhoc PCI was more frequent in radial 
group ( $n=54$ out of $155,34.8 \%)$ than in femoral group ( $n=44$ out of $225,19.6 \%$ ) with $p=0.01$. Stent was deployed in more than $90 \%$ in both groups. The mean diameter of the stents was larger in the TFA group, but no significant difference was detected with regard to mean number and total length of stents for each patient (table IV).

Contrast volume in between two groups was pretty similar with $p=0.226$. The incidence of other secondary endpoints was also not statistically significant. TRA was associated with lower rate of vascular complications and access site-related bleeding. Major complications were limited to 2 cases of acute renal failure and 1 cerebrovascular event in the TFA group, and 1 case of acute renal failure in the TRA group $(p=N S)$. Three failed cases of TRA necessitated crossover to TFA: One was due to the spasm of the radial artery; two were due to the tortuosities of the upper arms. There were no crossovers from TFA to TRA.

Initially, the majority of procedures were TFA, with a trend toward TRA during the study period. Learning curves for choosing the access site among the operators were distinct. In first year of the study, $81.5 \%$ of the cases were performed by femoral access. In second year, it was $66.5 \%$ with femoral access. In the last year of the study period, choice of the operator shifted abruptly towards radial access with $25.7 \%$ in the femoral \& $74.3 \%$ in radial group (Figure 1).

\section{Discussion}

This retrospective analysis shows that angiography and intervention of post-CABG patients can be safely performed via left TRA without significantly altering procedure time and fluoroscopy dose when compared with TFA. TRA is associated with a lower rate of access site related bleeding and a shortened post procedure stay.

Patients with a history of CABG usually have severe coronary lesions and are at high risk of cardiovascular events. Although the graft works well right after the bypass surgery, the long-term patency of the graft raises concerns. Saphenous vein graft (SVG) and the internal mammary artery (IMA) are estimated to block up again within 10 years in $40 \%$ and $15 \%$ of the post-CABG patients, respectively.5A second $\mathrm{CABG}$ surgery was not suggested because of the serious chest tissue adhesion and the increased risk of death after the surgery. ${ }^{6}$ However, PCI was still effective in treating occluded grafts.

The proportion of patients presenting with acute coronary syndrome and previous CABG surgery is around $13 \%$ internationally. ${ }^{12}$ The expectation is that these percentages will continue to increase and that patients with coronary grafts will continue to make up a significant proportion of patients undergoing acute or elective coronary angiography. ${ }^{13}$ While there are numerous studies to support the feasibility and safety of TRA of native coronaries, evidence is limited for performing graft angiography.

Transradial approach PCI has been increasingly used since its first successful application in 19937 not only because of the easier puncturing and hemostasis, but also for the better survival rate in certain patients. ${ }^{8,9}$ Han et al. found similar rates of short-term major adverse cardiac and cerebrovascular events between TRA and TFA $(1.5 \%$ vs. $5.4 \%, \mathrm{P}=0.479)$ in post-CABG patients undergoing angiography or PCI. ${ }^{18}$ Bundhoo et al. and Ziakas et al. reported similar short-term death and MACE in post-CABG patients undergoing SVG PCI. ${ }^{19,12}$ Consistent with these results, the present study showed similar procedure success and shortterm clinical outcomes between TRA and TFA.

Access site-related bleeding accounts for approximately $50 \%-80 \%$ of all major bleeding events in patients undergoing PCI. ${ }^{13}$ A recently published meta-analysis showed that the introduction of TRA decreased the risk of access site related bleeding by $73 \% .{ }^{14}$ This reduction could lead to better patient outcomes. ${ }^{15,16}$ More BARC 2 bleeding was detected in the TFA group than in the TRA group, indicating the benefit of TRA in reducing nuisance bleeding, even under the frequent use of GP IIb/IIIa inhibitors. ${ }^{17}$ The rates of access site complications were also similar between TRA and TFA $(5.1 \%$ vs. $7.0 \%, \mathrm{P}=0.22)$.

The majority of procedures performed in this analysis were TFA. Despite the preference for and experience in TFA, in addition to the initial TRA learning curve, no significant difference in procedural time and fluoroscopy dose was seen between the two groups. It is recognized that there 
will be a period of adjustment when operators change from TFA to TRA and it is estimated that even in experienced operators, it may take up to 25 TRA cases to achieve reasonable proficiency. Due to this learning curve with TRA, there have been concerns that patients and operators may be exposed to longer procedure times and radiation exposure. However, it has been shown that as operators become more experienced in TRA, procedure time and radiation exposures become comparable to TFA procedures. ${ }^{14}$

Reduced procedure times are important, not just for patient comfort, but also for improving catheter laboratory efficiency and therefore the cost effectiveness of angiography. Previous studies have already shown that TRA is more cost effective than TFA due to earlier ambulation and time to discharge. ${ }^{15}$ Our study revealed that the important procedural variable of procedure time, in addition to radiation dose, was unaffected by transradial access route choice for CABG patients, which may result in improved cost efficiency and patient satisfaction, without affecting patient safety. Fluoroscopy dose remains one of the main safety concerns in coronary angiography, due to the link between radiation exposure and malignancy in operators and patients. ${ }^{16,17}$ Importantly, we have been able to show that there was no significant difference in radiation dosage between TFA and TRA groups.

Michael et $\mathrm{al}^{3}$ found that TRA resulted in longer procedure times, but no statistically significant increase in patient radiation exposure. Interestingly, in the subgroup of patients who underwent PCI, there was no significant difference between TRA and TFA in regard to procedural time and radiation exposure. There was no significant crossover rate from radial to femoral route of $2 \%$. This crossover rate may have been partly attributable to trainee involvement as first operators and their underlying inexperience in TRA, with this inexperience potentially being a major contributor to the prolonged procedural times in the TRA group. Our results are comparable with two similar sized retrospective studies, where there was no difference found in procedural time and radiation exposure in patients with coronary grafts undergoing $\mathrm{PCI}^{18}$ and diagnostic angiography. ${ }^{19}$ Both of these studies involved over 300 patients and had similar crossover rates from radial to femoral route of around $4 \%$. The postprocedure stay was shortened by almost 1day in the TRA group compared with that in the TFA group, which is attributed to patients' earlier ambulation.

These data were collected at a time when the cardiology department at our hospital transitioned from a primary femoral to a radial center. During the study, in keeping with a transition to a radial center, there was a significant trend toward TRA; by 2014, almost two-third of all procedures was performed via the radial artery.

\section{Conclusion}

Coronary angiography for post CABG patients through left radial approach seems to be effective, noninferior in terms of contrast volume, procedure \& fluoroscopy time \& other clinical endpoints comparing to femoral access. Learning curve of the operators for radial approach is an important predicator of effective results especially of this type of study population.

\section{Study Limitations}

The retrospective design was the natural weakness of our study. The selection of the route was not randomized but at the doctor's discretion, which may result in selection bias. However, most of the patients' baseline characteristics were similar between the TRA and TFA groups. All the PCIs were conducted only in one hospital, which may restrict the extrapolation of the result to the general condition. Considering that all the interventionists had great expertise on TRA, in the present study, further investigation is needed to determine the performance success for TRA beginners.

Conflict of interest: We have no conflict of interest.

\section{References}

1. Jolly SS, Yusuf S, Cairns J, et al. Radial versus femoral access for coronary angiography and intervention in patients with acute coronary syndromes (RIVAL): a randomised, parallel group, multicentre trial. Lancet. 2011; 377: 1409-20.

2. Romagnoli E, Biondi-Zoccai G, Sciahbasi A, et al. Radial versus femoral randomized investigation in ST-segment elevation acute 
coronary syndrome: the RIFLE-STEACS (Radial Versus Femoral Randomized Investigation in ST-Elevation Acute Coronary Syndrome) study. J Am CollCardiol. 2012; 60: 281-89.

3. Michael TT, Alomar M, Papayannis A, et al. A randomized comparison of the transradial and transfemoral approaches for coronary artery bypass graft angiography and intervention (the RADIAL-CABG trial). JACC CardiovascInterv. 2013; 6: 1138-44.

4. Brueck M, Bandorski D, Kramer W, Wieczorek M, Holtgen R, Tillmanns H. A randomized comparison of transradial versus transfemoral approach for coronary angiography and angioplasty. JACC CardiovascInterv. 2009; 2: 1047-54.

5. Neill J, Douglas H, Richardson G, Chew EW, Walsh S, Hanratty C. Comparison of radiation dose and the effect of operator experience in femoral and radial arterial access for coronary procedures. Am J Cardiol. 2010; 106: 936-40.

6. Cooper CJ, El-Sheikh RA, Cohen DJ, et al. Effect of transradial access on quality of life and cost of cardiac catheterization: a randomized comparison. Am Heart J. 1999; 138: $430-36$.

7. Roussanov O, Wilson SJ, Henley $\mathrm{K}$, et al. Costeffectiveness of the radial versus femoral artery approach to diagnostic cardiac catheterization. $J$ Invasive Cardiol. 2007; 19: 349-53.

8. Hamon M, Pristipino C, Di Mario C, et al. Consensus document on the radial approach in percutaneous cardiovascular interventions: position paper by the European Association of Percutaneous Cardiovascular Interventions and Working Groups on Acute Cardiac Care and Thrombosis of the European Society. Euro Intervention. 2013; 8: 1242-51.

9. Frangos C, Nobel S. How to transform you into a radialist: literature review. Cardiovasc Med. 2011; 14: 277-82.

10. Rao SV, Tremmel JA, Gilchrist IC, et al. Society for Cardiovascular Angiography and Intervention's Transradial Working Group. Best practices for transradial angiography and intervention: a consensus statement from the
SR Khan, CMSKabir, MZ Chowdhury et al.

Society for Cardiovascular Angiography and Intervention's Transradial Working Group. Catheter CardiovascInterv. 2014; 83: 228-36.

11. Chew D, French J, Briffa T, et al. Acute coronary syndrome care across Australia and New Zealand: the SNAPSHOT ACS study. Med J Aust. 2013; 199: 185-91.

12. Bertrand OF, Rao SV, Pancholy S, et al. Transradial approach for coronary angiography and interventions: Results of the first international transradial practice survey. JACC CardiovascInterv 2010; 3: 1022-31.

13. Amoroso G, Kiemeneij F. Transradial access for primary percutaneous coronary intervention: The next standard of care? Heart 2010; 96: 1341-4.

14. Burzotta F, Trani C, Hamon $\mathrm{M}$, et al. Transradial approach for coronary angiography and interventions in patients with coronary bypass grafts: Tips and tricks. Catheter CardiovascInterv 2008; 72: 263-72.

15. Mehran R, Rao SV, Bhatt DL, et al. Standardized bleeding definitions for cardiovascular clinical trials: A consensus report from the Bleeding Academic Research Consortium. Circulation 2011; 123: 2736-47.

16. Goldman S, Zadina K, Moritz T, et al. Longterm patency of saphenous vein and left internal mammary artery grafts after coronary artery bypass surgery: Results from a department of veterans affairs cooperative study. $\mathrm{J} A \mathrm{Am}$ CollCardiol 2004; 44: 2149-56.

17. Verheul HA, Moulijn AC, Hondema S, et al. Late results of 200 repeat coronary artery bypass operations. Am J Cardiol 1991; 67: 24-30.

18. Han H, Zhou Y, Ma H, et al. Safety and feasibility of transradial approach for coronary bypass graft angiography and intervention. Angiology 2012; 63: 103-8.

19. Bundhoo SS, Earp E, Ivanauskiene T, et al. Saphenous vein graft percutaneous coronary intervention via radial artery access: Safe and effective with reduced hospital length of stay. Am Heart J 2012; 164: 468-72. 